\title{
Comparative Study of Apple Cultivars Bred in Holovousy, Czech Republic
}

\author{
J. Blažek ${ }^{1}$ \\ ${ }^{1}$ Research Institute of Pomology, Holovousy, Czech Republic \\ Correspondence: J. Blažek, Research Institute of Pomology, Holovousy, Czech Republic. E-mail: \\ blazek@vsuo.cz
}

Received: May 3, 2013 Accepted: June 14, 2013 Online Published: June 17, 2013

doi:10.5539/jps.v2n3p113 URL: http://dx.doi.org/10.5539/jps.v2n2p113

\begin{abstract}
In an experimental orchard, 14 apple cultivars bred in Holovousy and registered in the Czech Republic during 1994-2011 have been evaluated for 12 years in comparison with four standard ones most commonly grown here. Trees were planted on M9 rootstock in the spacing of $4 \times 1 \mathrm{~m}$ and trained like spindles. Zuzana cv had the most vigorous trees. which was followed by Primadela and Resista. On the contrary, Selena had the smallest canopy, followed by Rubinstep, Vysočina and Julia. Regarding disease performance Primadela, Resista, Selena, Starkresa and Vysočina were entirely resistant to apple scab (Venturia inaequalis). Another three, Julia, Angold and Produkta were rated as highly tolerant to the disease. The highest levels of tolerance to powdery mildew were recorded on Meteor, Nabella and on the standard cultivar Rubin. Occurrence of fruit rot was very negligible on Starkresa, Benet, Vysočina and Meteor. The most productive was Rucla with a mean year harvest equal to 34.4 tons per hectare. In decreasing order, it was followed by Nabella, Resista, Produkta, Primadela, Angold and Vysocina, all of which were better than the standard ones. Regarding fruit size the largest one was Meteor followed by Jonagold, Angold, Benet and Nabella. The cultivar that was first in taste was Rucla, followed by Benet, Rubín, Rubinstep, Starkresa and Meteor.
\end{abstract}

Keywords: scab, mildew, tree vigour, yields, fruit quality

\section{Introduction}

The most important apple cultivars presently grown in the Czech Republic are Golden Delicious and Jonagold. The commercial growth of both the leaders requires, however, excessive orchard protection against the main diseases. Therefore, the principal aim of our research is the development of new substitutes of the leaders with much less demands for chemical protection and, therefore, also more acceptable for apple consumers (Blazek et al., 2006; Blažek, 2007b). Similar trends of the development exist also in other countries (Cline et al., 2010).

A breeding program aimed at developing new apple cultivars started in Holovousy during the early seventies of the last century. At its early stage it was based upon collaboration with Dr. L. F. Hough, who was engaged at Rutgers University, New Brunswick, New Jersey. He supplied seeds for several seasons from a great number of progenies derived by crossings between selected donors of Malus floribunda scab resistance and standard cultivars. The obtained seedlings were pre-selected for their disease resistance at an early stage and subsequently selected for other main economic characteristics, but their fruit quality was considered the most important. From that time, about 10,000 flowers from around 50 different parental combinations have been cross-pollinated at Holovousy every year. From seeds obtained in such a way, around 8,000 seedlings were yearly pre-selected for disease resistance or tolerance. After this pre-selection, up to 1,500 seedlings were each year budded on M 9 and were planted into orchards for evaluation in their fruiting stage. The most promising seedlings were included in comparative trials with commercial leaders and, subsequently, into the State variety trials as candidates for new cultivars.

The first apple cultivars released from this program were Julia, Nabella, and Selena, which were registered in 1994 (Blazek, 1993; Blazek \& Paprstein, 1993, Blazek et al., 1995). In the following year, the cultivar Angold was released (Blazek, 1997). Another three novelties from the program-Produkta, Resista, and Zuzana were registered within the year 1997 (Blazek, 1999). From the early part of this century, other new cultivars were released (Rubinstep, 2003; Blazek, 2001; Fragrance, 2004; Vysocina, 2006; Blazek, 2007a). All others have been released during the following years (Blazek \& Wit de, 2006; Blazek \& Krelinova, 2007). 
At the present time, the cultivars Golden Delicious, Jonagold, Gala, and Rubin are the most important in the Czech Republic with respect to acreage and production level (Buchtová, 2011). They have been used as the standard cultivars in this study.

\section{Material and Methods}

Experimental orchards were established in the spring of 1999 using one-year-old trees grafted on M 9 rootstock planted in spacings of $4 \times 1 \mathrm{~m}$. As standard cultivars in this study, Golden Delicious, Jonagold, Gala, and Rubin were used. All planted trees were produced in the commercial nursery of the institute at Holovousy. The location is characterised by an average yearly temperature of $8.1^{\circ} \mathrm{C}$, average rainfall of about $650 \mathrm{~mm}$ and altitude about $300 \mathrm{~m}$. The soil in the location is very good, having a deep tillage level and $\mathrm{pH}$ value about 7 . Data of each cultivar used in this study were measured or rated on at least 5 trees planted without replication. In the majority of the cultivars, however, a greater numbers of trees planted in replications were used. The orchard was maintained with clean herbicide strips under the tree canopies and with mulched grass along the alleyways. Trees were trained in the $\mathrm{r}$ spindle form and canopies were kept in reasonable size using pruning in the winter time. In some more vigorous cultivars, somewhat larger canopy volume was allowed to develop during recent years if necessary. Fertilising and spraying (based on integrated apple orchard protection guidelines) consisted of normal commercial practices with the exception of the first three years after orchard establishment when fungicide treatments were not applied due to the evaluation of cultivars regarding their susceptibility to common diseases, rated in August using a 1-9 scale $(9=$ no symptoms). Each year, phenological data concerning the time of flowering and optimum harvest ripening (based on standard indicators) for each cultivar were gathered. The start of flowering was defined by the date when $10 \%$ of flowers were open. The start of the harvest ripening was estimated according to typical fruit coloration and their ease in separation from spurs. During the harvest ripening season, all fruits were harvested and weights of the harvested fruit from each tree noted. The final estimation of the harvest maturity period for each cultivar was done based upon commonly used principles (Jaradat \& Assi, 2007).

At the end of the growing season, canopy dimensions and the trunk diameter of each tree were measured and used for calculation of the canopy volume and trunk-cross-section area (TCSA).

All fruit samples were immediately after their harvest placed in a cold store where they were kept permanently throughout their total storage life at a temperature regulated within 2 or 3 degrees $\mathrm{C}$. During this period, every fruit sample was organolepticaly evaluated at least two times in the case of autumn cultivars, but usually 3 or 4 times in others. With the results of these evaluations the length of the consume maturity period of each cultivar was estimated. For these evaluations, several fruits per sample were randomly taken from the cold store the day before and placed in the laboratory where the temperature was kept at the level of about $20{ }^{\circ} \mathrm{C}$. The evaluation itself consists in weighing of fruits, estimation of cover colour area (\%) and judging of fruit appearance, flesh fitness, and total taste using a rating scale 1-9 in which number 9 indicates the best performance.

These data were tested by analysis of variance. Cultivar means were separated by Tukey's "least significance difference" test at $\mathrm{P}<0.05$.

\section{Results and Discussion}

\subsection{Tree Vigour}

Two parameters that characterised tree vigour of the evaluated cultivars at three different age stages of the orchard are presented in Table 1. The most vigorous according to the TCSA (Trunk cross sectional area) measured at the final stage were the cultivars Zuzana, Produkta, Primadela, and Jonagold (Figure 1). On the contrary, the least vigorous ones were Selena, followed by Rubinstep, Vysocina, and Benet. The TCSA of Selena was about $54 \%$ smaller than that of Zuzana. The differences among the rest of the cultivars were quite small and mostly statistically insignificant.

Table 1. Tree size parameters of evaluated cultivars measured in three different years

\begin{tabular}{lllllll}
\hline Cultivar & \multicolumn{3}{l}{ Trunk cross section area $\left(\mathrm{cm}^{2}\right)$} & \multicolumn{3}{l}{ Canopy volume $\left(\mathrm{m}^{3}\right)$} \\
\cline { 2 - 7 } & 2005 & 2008 & 2012 & 2005 & 2008 & 2012 \\
Angold & 19.6 & 33.4 & 47.1 & 2.1 & 2.2 & 2.2 \\
Benet & 14.2 & 29.8 & 45.5 & 1 & 1.3 & 1.5 \\
Gala & 20.8 & 38.7 & 56.6 & 1.7 & 1.8 & 2 \\
\hline
\end{tabular}




\begin{tabular}{lllllll}
\hline Golden Del. & 17 & 33 & 49.1 & 1.6 & 1.7 & 1.9 \\
Jonagold & 24.4 & 40.9 & 57.4 & 2.3 & 2.3 & 2.4 \\
Julia & 18.5 & 32.9 & 47.2 & 1.3 & 1.6 & 1.8 \\
Meteor & 15.4 & 32.9 & 50.3 & 2 & 2.3 & 2.5 \\
Nabella & 14 & 33 & 52 & 1.4 & 1.8 & 2.2 \\
Primadela & 21.2 & 41.2 & 61.1 & 2.8 & 2.8 & 2.7 \\
Produkta & 19.4 & 41.8 & 64.3 & 2.4 & 2.6 & 2.7 \\
Resista & 17.7 & 36.2 & 54.8 & 2.4 & 2.5 & 2.7 \\
Rubín & 12.4 & 30.5 & 48.6 & 1.7 & 1.9 & 2.1 \\
Rubinstep & 12.9 & 25.7 & 38.4 & 1.1 & 1.4 & 1.7 \\
Rucla & 19.4 & 35.9 & 52.4 & 1.7 & 2 & 2.4 \\
Selena & 10.1 & 22.1 & 34.2 & 0.8 & 1.1 & 1.3 \\
Starkresa & 17.1 & 35.9 & 54.7 & 2.2 & 2.3 & 2.5 \\
Vysočina & 15 & 28.2 & 41.4 & 1.3 & 1.6 & 1.8 \\
Zuzana & 20.4 & 45.9 & 71.5 & 2.7 & 2.8 & 2.8 \\
Average & 17.2 & 34.3 & 51.5 & 1.8 & 2 & 2.2 \\
LSD (P=0.05) & 2.8 & 4.4 & 5.9 & 0.47 & 0.36 & 0.32 \\
\hline
\end{tabular}

$\mathrm{cm}^{2}$

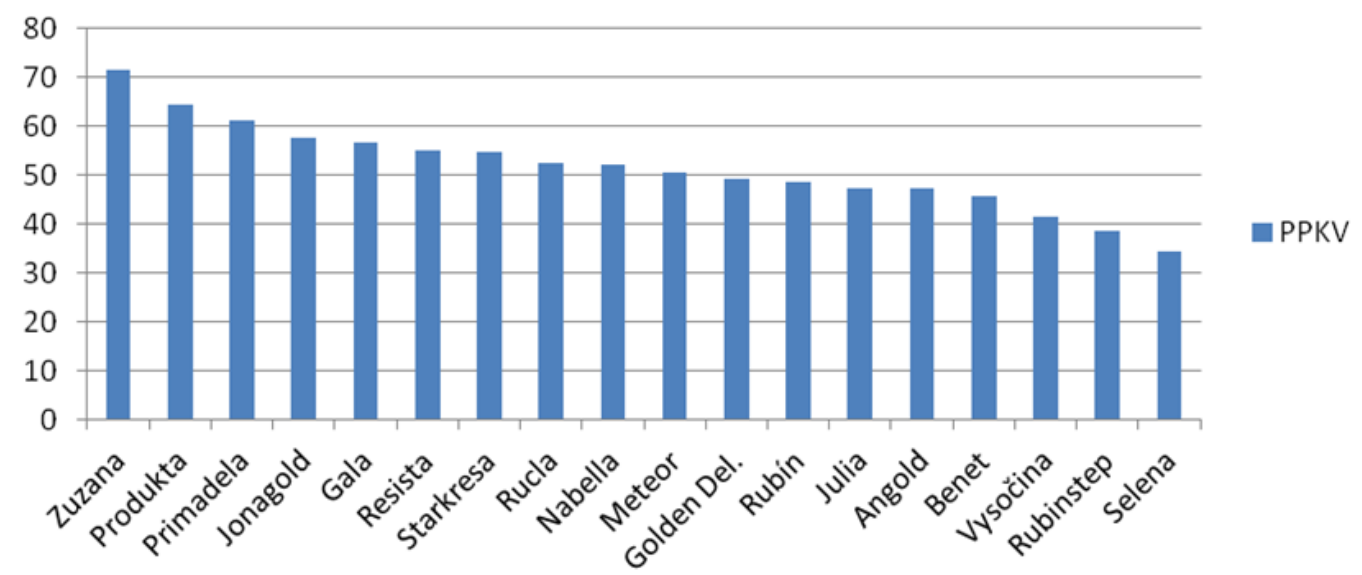

Figure 1. Cultivars ranged in downward ordered according to tree vigor based upon trunk-cross-section area in 2012

Considering the development of canopy volume, the most vigorous from the start was Primadela, followed by Zuzana and Resista. They reached the maximal size of their canopy volume as early as 2005, and onwards had to be more strongly pruned every year. On the contrary, Selena was again distinguished by the smallest canopy, followed by Rubinstep, Vysočina, and Julia. Trees of the last mentioned summer cultivar were characterised by compact growth habit.

Tree vigour of the standard cultivars was roughly in range according to a previous publication (Cline et al., 2010; Crassweller et al., 2011; Kenis \& Keulemans, 2007). Information on the higher demands of Jonagold for more dwarfing rootstock regarding its vigour control was recently reported by another study (Vercammen \& Gomand, 2011). 


\subsection{Susceptibility to Diseases and Fruit Disorders}

Mean values of cultivar ratings for apple scab (Venturia inaequalis), powdery mildew (Podosphaera leucotricha), and incidence of main fruit disorders are presented in Table 2. Regarding scab, five cultivars - Primadela, Resista, Selena, Starkresa, and Vysočina proved to be completely resistant. Another three - Julia, Angold, and Produkta were rated as highly tolerant to the disease. All other evaluated cultivars scored higher than the susceptible standards and can be classified as less susceptible. These results are more or less in agreement with our previous finding (Blazek et al., 2006). The scab resistance of cultivars Angold and Produkta is based on its donor (A 28/39) found in the progeny of Antonovka (Blažek, 1997). In the case of Julia, it came from the cultivar Discovery which originated in England. The total scab resistance of the first 5 cultivars is based on several back crosses of its selected donors derived from Malus floribunda 821 and cultivars or selections possessing high quality of fruits (Blažek \& Křelinová, 2006).

Table 2. Incidences of diseases and fruit disorders (1-very high. 9 - no)

\begin{tabular}{cccccccc}
\hline \multirow{2}{*}{ Cultivar } & \multicolumn{2}{c}{ Scab } & \multicolumn{2}{c}{ Powdery mildew } & Bitter rot & Biter pit & Water core \\
\cline { 2 - 8 } & mean & max. & mean & max. & mean & max. & max. \\
\hline Angold & 8.3 & 7 & 6.2 & 4 & 5.2 & 9 & 9 \\
Benet & 7.3 & 5 & 7.4 & 6 & 8.1 & 8 & 9 \\
Golden Del. & 5.3 & 2 & 6.7 & 5 & 7.7 & 5 & 9 \\
Julia & 8.5 & 8 & 7.8 & 7 & 7.8 & 9 & 9 \\
Meteor & 7.6 & 6 & 8.4 & 7 & 8 & 8 & 9 \\
Rubinstep & 7.2 & 6 & 7.4 & 6 & 6 & 7 & 9 \\
Rucla & 7.9 & 7 & 7 & 6 & 6.5 & 8 & 9 \\
Zuzana & 7.8 & 7 & 7.1 & 6 & 6.4 & 7 & 9 \\
Gala & 6.5 & 2 & 7.8 & 6 & 6.3 & 8 & 8 \\
Primadela & 9 & 9 & 7.9 & 7 & 6.6 & 8 & 8 \\
Rubín & 7.8 & 6 & 8.2 & 7 & 6.3 & 5 & 8 \\
Selena & 9 & 9 & 7.5 & 6 & 7.5 & 6 & 8 \\
Starkresa & 9 & 9 & 7.7 & 6 & 8.4 & 9 & 8 \\
Vysočina & 9 & 9 & 7.1 & 6 & 8.1 & 8 & 8 \\
Jonagold & 7.2 & 4 & 5.3 & 3 & 6.1 & 4 & 7 \\
Resista & 9 & 9 & 6.6 & 5 & 7.4 & 7 & 7 \\
Produkta & 8.1 & 7 & 7.5 & 6 & 7.8 & 7 & 6 \\
Nabella & 7.8 & 7 & 8.1 & 7 & 7.5 & 7 & 5 \\
Mean & 8.3 & & 7.3 & & 7.1 & & \\
L.S.D. P $\geq 0.05$ & 0.34 & & 0.22 & & 0.46 & & \\
\hline
\end{tabular}

The majority of the new cultivars did not have any problems related to powdery mildew incidence. The highest levels of field tolerance to this disease were recorded on Meteor, Nabella, and on the standard cultivar Rubín. Another eight cultivars were rated as less susceptible: Primadela, Julia, Gala, Starkresa, Produkta, Selena, Benet, and Rubinstep. Medium occurrence of the disease was recorded only on Angold and Resista, but even these two were in this respect better than the standard cultivar Jonagold.

Significant differences within the evaluated set of cultivars were further observed in the incidence of fruit disturbances. The relatively highest incidence of fruit rot was observed on Angold. On the other hand, rotting of fruits in the cultivars Starkresa, Benet, Vysočina, and Meteor was very negligible. No bitter pit was observed on fruits of Angold, Julia, and Starkresa, whereas all the standards except Gala had the highest problems with this disorder. Nabella and Produkta had serious problems with the water cote, but Resista and the standard cultivar 
Jonagold were not much better.

\subsection{Yields and Productivity}

Annual mean yields per tree of the evaluated cultivars in this study are presented in Table 3. The level of these yields was negatively influenced in the year 2011, when as a consequence of extreme flower damage by frosts the harvest was extremely low. The most productive in this category was Rucla, having a mean annual harvest per tree equal to $15.4 \mathrm{~kg}$. After converting to the yield per area, this value is equal to $34.4 \mathrm{t} / \mathrm{ha}$. Besides Rucla, the cultivars Nabella, Resista, Produkta, Primadela, Angold, and Vysočina followed in decreasing order, all of which were better than the standard ones. On the contrary, the lowest yields were found in the standard cultivar Rubin; furthermore, Zuzana and Julia had a mean year harvest not much higher than $20 \mathrm{t} / \mathrm{ha}$. The range of cultivars according to this criterion is illustrated also by Figure 2 .

Table 3. Mean annual yields per tree in $\mathrm{kg}$

\begin{tabular}{cccccccccc}
\hline Cultivar & Yield mean up to 2005 & 2006 & 2007 & 2008 & 2009 & 2010 & 2011 & 2012 & Total \\
\hline Angold & 7.2 & 17.3 & 15.9 & 24.5 & 6.7 & 9.8 & 2.6 & 30.6 & 150.6 \\
Benet & 7 & 10.3 & 10.2 & 17.6 & 18.6 & 13.1 & 1.7 & 20.1 & 133.4 \\
Gala & 7.6 & 19.3 & 11.8 & 11.3 & 9.5 & 15.5 & 1.6 & 25.8 & 140.5 \\
Golden Delicious & 8.4 & 17.6 & 6.1 & 23.7 & 2.9 & 15.6 & 1.8 & 21 & 139.3 \\
Jonagold & 7.7 & 15.6 & 18.1 & 28.2 & 6.3 & 15.6 & 0.9 & 16.4 & 147.5 \\
Julia & 8.6 & 11.4 & 6 & 10.8 & 12.4 & 8.8 & 3.1 & 19.8 & 123.8 \\
Meteor & 5.9 & 15.5 & 23.3 & 16.9 & 11.6 & 7.6 & 9.3 & 15.4 & 134.9 \\
Nabella & 6.3 & 12.2 & 18.7 & 27.4 & 23.5 & 19.9 & 4.4 & 26.2 & 169.8 \\
Primadela & 9.8 & 23.3 & 19.4 & 19.8 & 7.4 & 4.7 & 2.6 & 23.2 & 159.1 \\
Produkta & 10 & 24.8 & 8.4 & 24.2 & 4.7 & 8.3 & 1 & 28.8 & 160.2 \\
Resista & 7.2 & 18 & 19.6 & 24.9 & 6.2 & 17.4 & 3.4 & 29.8 & 162.4 \\
Rubín & 5 & 11.5 & 18.1 & 10.8 & 10.7 & 15.8 & 0.6 & 14.2 & 111.4 \\
Rubinstep & 7.4 & 15.1 & 3.2 & 19.1 & 1.7 & 13.3 & 0.7 & 27.5 & 125 \\
Rucla & 10 & 21.4 & 20.2 & 27.1 & 11.4 & 19.8 & 1.1 & 23.2 & 184 \\
Selena & 7.7 & 15.9 & 11.6 & 29.2 & 8.8 & 9.4 & 2.8 & 19.7 & 143.9 \\
Starkresa & 6.8 & 19.5 & 20.5 & 20.2 & 8 & 8 & 4.5 & 15.5 & 136.9 \\
Vysočina & 9.7 & 14.4 & 13.1 & 15.8 & 16.3 & 10.7 & 2.6 & 17.2 & 148 \\
Zuzana & 5.5 & 15 & 17.2 & 16.6 & 3.8 & 4.8 & 3.3 & 27.4 & 121.3 \\
Total & 7.6 & 16.6 & 14.5 & 18.8 & 8.1 & 12.1 & 3.4 & 22.8 & 142 \\
LSD (P=0.05) & 1.3 & 1.9 & 2.7 & 2 & 3.2 & 1.5 & 1.1 & 2.1 & 3.9 \\
\hline & & & & & & & & &
\end{tabular}




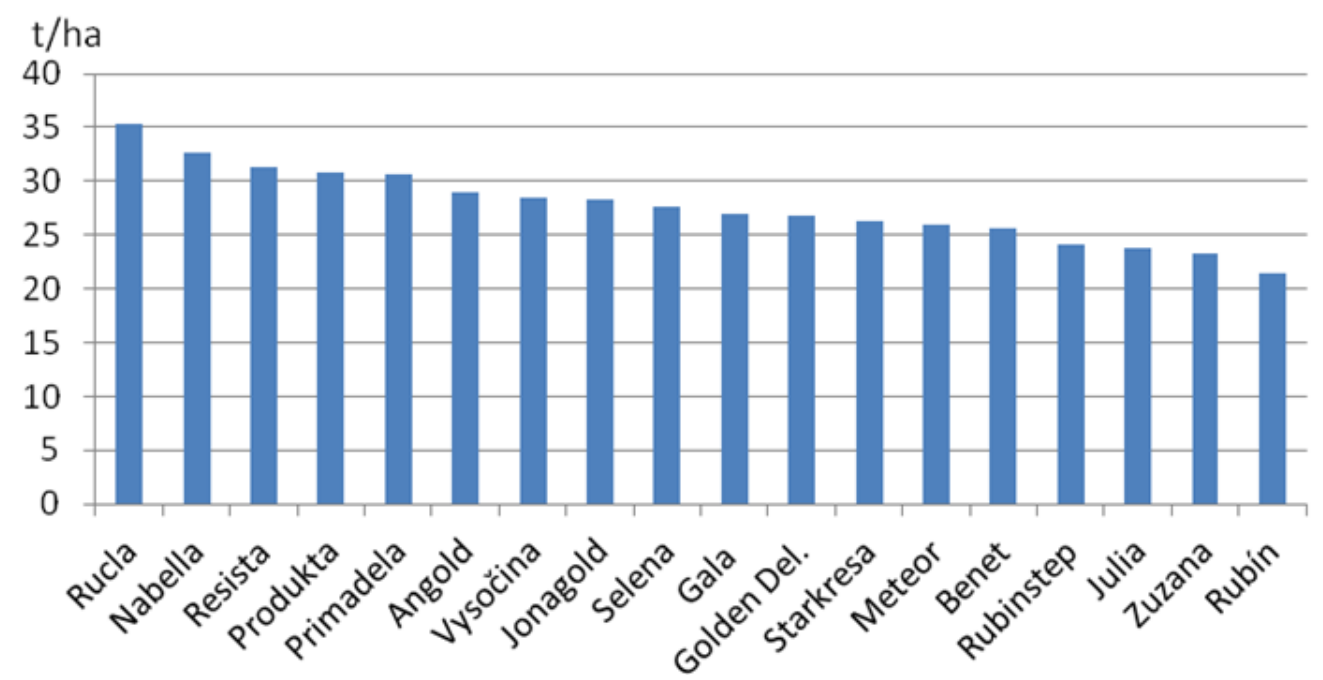

Figure 2. Cultivars ranged according to mean annual yields calculated per area

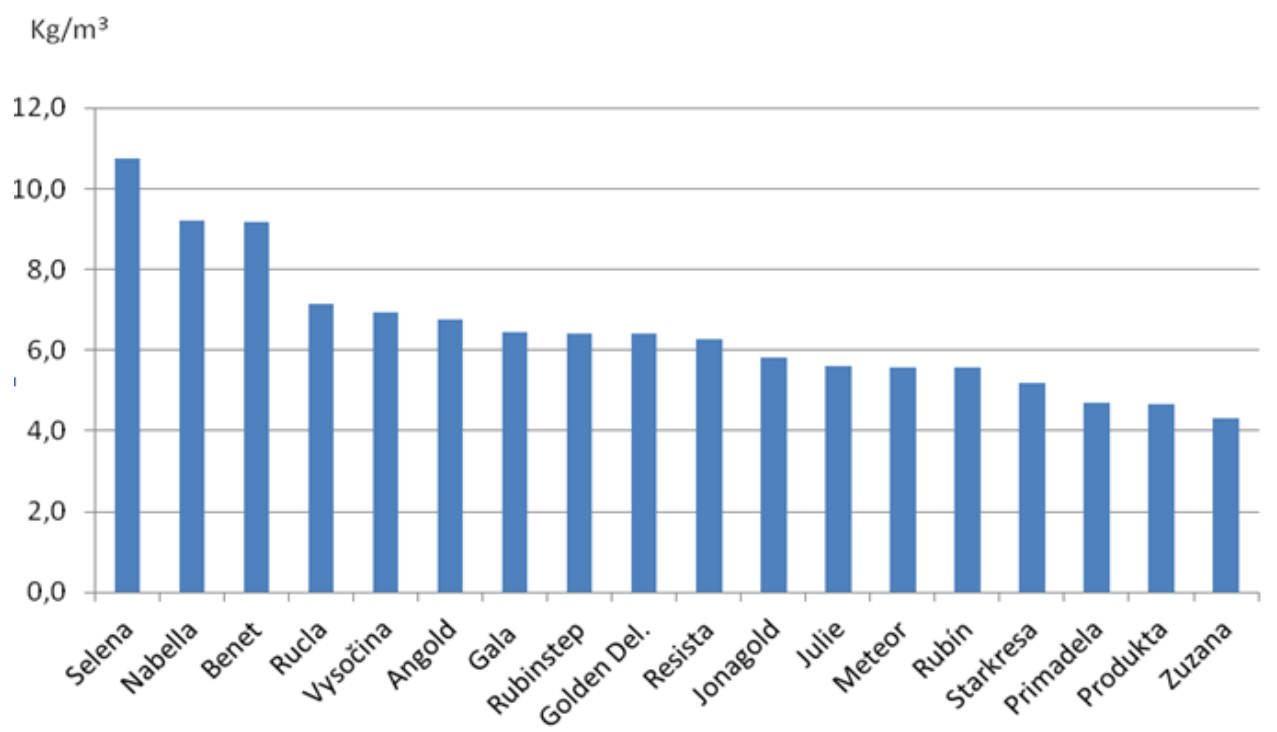

Figure 3. Cultivars ranged according to mean specific yields 2006-11 calculated for $1 \mathrm{~m}^{3}$ of the canopy volume

The highest specific yields calculated for $1 \mathrm{~m}^{3}$ of the canopy volume in the final years of the study were observed in Selena (Figure 3). It was followed in this characteristic by Nabella, Benet, and Rucla. Zuzana was again distinguished by the lowest specific yield, but this time it was followed by Produkta and Primadela. This was obviously connected to the excessive growth vigour of these cultivars.

\subsection{Time of Flowering}

The season of flowering of eight cultivars was classified as medium (Table 4). Except for the very early flowering Rubinstep and very late flowering Meteor and Resista, they should be well pollinated every year with all the others. While during the establishment of new orchards, carriers of both extremes should be combined for proper pollination only with cultivars included in neighbouring groups (for example, very early with early flowering ones). 
Table 4. Time of fruit ripening and selected characteristics of fruits

\begin{tabular}{|c|c|c|c|c|c|c|c|c|}
\hline Cultivar & $\begin{array}{l}\text { Time of } \\
\text { flowering }\end{array}$ & $\begin{array}{l}\text { Start of the harvest } \\
\text { (mean day) }\end{array}$ & $\begin{array}{l}\text { Consume } \\
\text { season }\end{array}$ & $\begin{array}{l}\text { Consume } \\
\text { season }\end{array}$ & $\begin{array}{l}\text { Fruit } \\
\text { weight (g) }\end{array}$ & $\begin{array}{l}\text { Fruit } \\
\text { appearance }\end{array}$ & $\begin{array}{l}\text { Flesh } \\
\text { firmness }\end{array}$ & $\begin{array}{l}\text { Total } \\
\text { taste }\end{array}$ \\
\hline Angold & Early & Sept. 28 & Dec. & June & 227.8 & 6.6 & 5.7 & 7 \\
\hline Benet & Medium & Oct. 3 & Dec. & June & 218.5 & 7.9 & 7.1 & 8.1 \\
\hline Gala & Late & Sept. 23 & Nov. & April & 135 & 7.6 & 6.3 & 7.3 \\
\hline Golden Del. & Late & Oct. 5 & Dec. & May & 183.4 & 7.1 & 5.5 & 7.1 \\
\hline Jonagold & Medium & Sept. 25 & Nov. & May & 229.1 & 7.8 & 5.3 & 6.9 \\
\hline Julia & Early & 18-Jul & July & August & 146.3 & 7.5 & 7 & 6.6 \\
\hline Meteor & Very late & Oct. 3 & Dec. & July & 252 & 7.8 & 6.4 & 7.5 \\
\hline Nabella & Medium & Sept. 8 & Oct. & Dec. & 206.4 & 6.5 & 4.3 & 5.5 \\
\hline Primadela & Early & Sept. 26 & Nov. & May & 168.9 & 7.6 & 5.9 & 7.3 \\
\hline Produkta & Medium & Sept. 25 & Nov. & Mar. & 185.7 & 5.9 & 5.5 & 5.1 \\
\hline Resista & Very late & Oct. 8 & Nov. & May & 178.3 & 6 & 5.3 & 5.8 \\
\hline Rubín & Medium & Sept. 15 & Oct. & Feb. & 202.6 & 7.9 & 5.6 & 7.9 \\
\hline Rubinstep & V. early & Sept. 21 & Oct. & April & 184 & 8.1 & 5.8 & 7.7 \\
\hline Rucla & Medium & Sept. 27 & Dec. & June & 159.3 & 7.7 & 7.5 & 8.1 \\
\hline Selena & Medium & Sept. 16 & Oct. & Jan. & 158.6 & 7.2 & 5.1 & 6.6 \\
\hline Starkresa & Late & Oct. 9 & Dec. & May & 160.9 & 7.5 & 6.9 & 7.6 \\
\hline Vysočina & Early & Sept. 22 & Oct. & March & 189.2 & 6.1 & 5 & 6.9 \\
\hline Zuzana & Medium & Oct. 6 & Jan. & June & 201 & 5.3 & 7.7 & 5.3 \\
\hline
\end{tabular}

\subsection{Time of Harvest Ripening}

The harvest season of the evaluated cultivars started with the summer cultivar Julia, which had a mean date of July 18 (Table 4). It was followed by Nabella (Sept. 8), Rubin (Sept. 15) and Selena (Sept. 16). Another eight cultivars were harvested on average during the last week of September. The remaining six cultivars were mostly ready for harvest at the beginning of October. Among this group, Resista and Starkresa could be classified as the latest ones.

\subsection{Consume Season}

With the exception of the summer cultivar Julia and autumn ones Nabella and Selena, the rest of the cultivars are well storable varieties suitable to consume for several months at least. The best storable among them is Meteor, which has fruits that can be frequently kept in good quality till the next season. Also Angold, Benet, and Zuzana are very well storable cultivars suitable for use till June.

\subsection{Fruit Characteristics}

The largest fruits in this study were found in Meteor, with a mean fruit weight equal to $252 \mathrm{~g}$ (Table 4). In decreasing order, it was followed in this characteristic by Jonagold, Angold, Benet and Nabella. On the other hand, the relatively smallest fruits on average were found in the standard cultivar Gala (mean fruit weight $135 \mathrm{~g}$ ). Significantly larger, however, were fruits of Julia, and Selena placed nearest to it in increasing order.

Cultivar Rubinstep was distinguished by the most attractive fruits, having a mean score for their appearance equal to 8.1. It was followed in this characteristic by Benet (Figure 4), Rubín, Jonagold, Meteor and Rucla (Figure 4). On the contrary, the lowest mean values in fruit appearance were received by the cultivars Zuzana, Produkta, Resista, and Vysocina. 

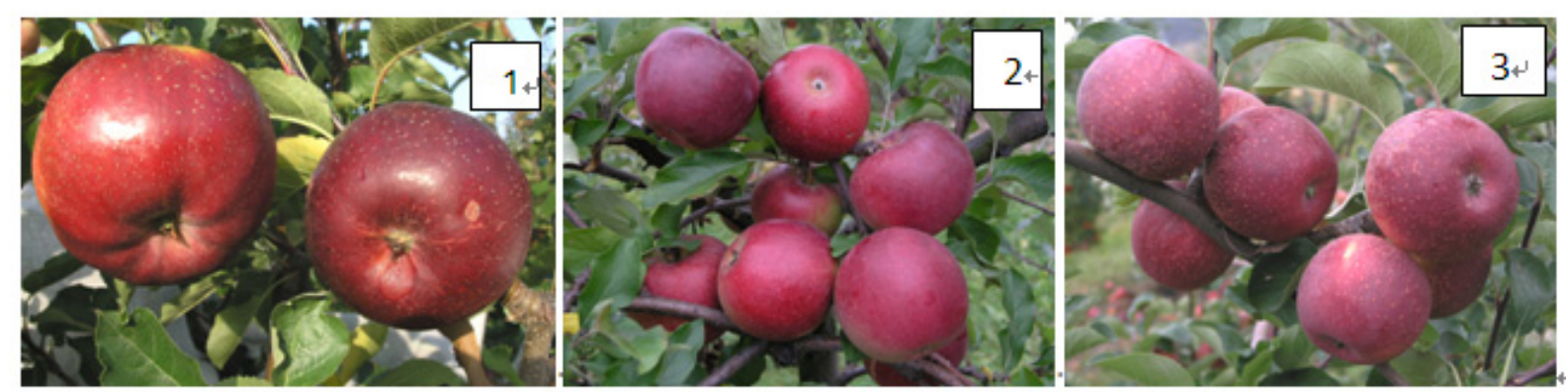

Figure 4. Fruits of cultivars Benet (1), Meteor (2) and Rucla (3)

Relatively smaller differences among cultivars were found in flesh firmness. The highest values of this parameter were found in the cultivars Zuzana, Rucla, Benet, and Julia, whilst Nabella was the poorest in this respect.

Regarding general eating quality of fruits indicated by a scoring for total taste, the top one on average was Rucla. It was followed in this characteristic in decreasing order by Benet, Rubín, Rubinstep, Starkresa, and Meteor. On the contrary, the lowest scores in this respect were received by Produkta, Zuzana, Nabella, and Resista. This rating of the majority of the cultivars is mainly in agreement with our previous finding (Blazek \& Krelinova, 2006).

\section{Conclusions}

The majority of new cultivars have much less demands for chemical protection against diseases. Five of them (Primadela, Resista, Selena, Starkresa and Vysočina) are completely resistant to scab and another three - Julia, Angold and Produkta are highly tolerant to the disease. The highest levels of tolerance to powdery mildew were recorded on Meteor and Nabella.

There are large differences among the cultivar set in tree vigour. Selena cv had the weakest tree growth potential, having a final tree canopy size about $54 \%$ smaller than the most vigorous Zuzana $\mathrm{cv}$.

Rucla was distinguished by the highest yield potential, having a mean year harvest equal to $34.4 \mathrm{t} / \mathrm{ha}$. In decreasing order, it was followed by Nabella, Resista, Produkta, Primadela, Angold and Vysocina, all of which were better than the standard ones.

A range of new cultivars has better fruit storage potential than the standards. The most exceptional among them is Meteor; its fruits can frequently be kept in good quality till the next season. Also Angold, Benet, and Zuzana are very well storable cultivars suitable for use till June.

The cultivar Rubinstep is distinguished by the most attractive fruits. It is followed in this characteristic by Benet, Meteor and Rucla.

The cultivar Rucla had the best scoring for total eating quality of fruits. It is followed in this characteristic in decreasing order by Benet, Rubinstep, Starkresa, and Meteor.

\section{Acknowledgements}

This work was realized in the framework of research projects MSM2527112101 and RO0613. The infrastructure of CZ.105/2.1.00/03.0116 was used.

\section{References}

BLAŽEK, J. (1993). Description of 'Selena' a new scab resistant apple cv. Vědecké práce ovocnářské, 13, 141-143.

BLAŽEK, J. (1997). New apple cultivar 'Angold'. Vědecké práce ovocnářské, 15, 143-148.

BLAŽEK, J. (1999). Apple cultivar 'Resista'. Vědecké práce ovocnářské, 16, 109-112.

BLAŽEK, J. (2001). Apple cultivar 'Rubinstep'. Védecké práce ovocnářské, 17, 163-165.

BLAŽEK, J. (2007a). Apple cultivar 'Vysočinaa'. Vědecké práce ovocnářské, 20, 155-157.

BLAŽEK, J. (2007b). Orchard performance and fruit quality of 50 apple cultivars grown or tested in commercial orchards of the Czech Republic. Horticultural Science, 34(3), 96-106.

BLAŽEK, J., KLOUTVOR, J., PAPRŠTEIN, F., \& VONDRÁČEK, J. (1995). New apple cultivar 'Nabella'. 
Vědecké práce ovocnářrské, 14, 119-125.

BLAŽEK, J., HLUŠIČKOVÁ, I., \& VÁVRA, R. (2006). Scab (Venturia inaequalis) and mildew (Podosphaera leucotricha) on cultivars Grown in commercial apple orchards in the Czech Republic. Proc. from International conference of perspectives in European fruit growing held in Lednice, Czech Republic, on October 18-20, 265-269.

BLAŽEK, J., KLOUTVOROVÁ, J., \& KŘELINOVÁ, J. (2006). Incidence of storage diseases on apples of selected cultivars and advanced selections grown with and without fungicide treatments. Horticultural Science, 33(3), 87-94.

BLAŽEK, J., \& KŘELINOVÁ, J. (2006). Seven-year orchard performance of eleven new apple cultivars from Holovousy in comparison with some commonly grown ones. Hort. Sci. (Prague), 33(4), 131-139.

BLAŽEK, J., \& KŘELINOVÁ, J. (2007). Selected fruit quality characteristics of new apple cultivars bred in Holovousy in comparison to some commonly grown standards. Vědecké práce ovocnáršsé, 20, 53-61.

BLAŽEK, J., \& PAPRŠTEIN, F. (1993). Growth, yields and fruit quality of Selena cv. in comparison with several common cultivars. Védecké práce ovocnář́ské, 13, 119-127.

BLAŽEK, J., \& VONDRÁČEK, J. (1999). New apple cultivar 'Zuzana'. Vědecké práce ovocnářrské, 16, 113-116.

BUCHTOVÁ, I. (2011). Situational and far-sighted report for fruits. October 2011. Ministry of Agriculture, Těšnov 17, 11705 Prague 1, CZ.

Cline, J. A., NORTON, D., EMBREE, C. G., \& PRIVE, J. P. (2010). Performance of Jonagold, McIntosh and Novaspy on three new semi-dwarf apple rootstocks in eastern Canada. Can. J. Plant Sci., 90, 877-883. http://dx.doi.org/10.4141/cjps09186

CRASSWELlER, R. M., SMITH, D. E., \& TUKEY, L. D. (2001). Performance of 'Golden Delicious'and 'Delicious' apples on dwarfing Rootstocks. Acta Hort., 557, 47-54.

JARADAT. S., \& EL ASSI, N. (2007). Prediction of the optimum harvest date for three apple (Malus domestica Borkh.) cultivars in Jordan. Acta Hort., 741, 73-80.

KENIS, K., \& KEULEMANS, J. (2007). Study of tree architecture of apple (Malus $x$ domestica Borkh.) by QTL analysis of growth traits. Mol Breeding, 19, 193-208.

VERCAMMEN, J., \& GOMAND, A. (2011). Search for a more dwarfing rootstock for Jonagold apple. Acta Hort, 903, 355-362. http://dx.doi.org/10.1007/s11032-006-9022-5

\section{Copyrights}

Copyright for this article is retained by the author(s), with first publication rights granted to the journal.

This is an open-access article distributed under the terms and conditions of the Creative Commons Attribution license (http://creativecommons.org/licenses/by/3.0/). 